\title{
Medication administered to children from 0 to 7.5 years in the Avon Longitudinal Study of Parents and Children (ALSPAC)
}

\author{
J. Headley $•$ K. Northstone
}

Received: 3 August 2006 / Accepted: 29 October 2006 / Published online: 3 January 2007

(C) Springer-Verlag 2007

\begin{abstract}
Objective To present data on the parentally-reported use of all types of medicinal products in children from 0 to 7.5 years, in a large cohort in south-west England.

Methods Participants in the population-based Avon Longitudinal Study of Parents and Children (ALSPAC) have been sent self-completion postal questionnaires since they were enrolled during pregnancy. The use of medicinal products has been obtained from questionnaires sent out when the study children were 4 weeks, 54, 78 and 91 months old.

Results The data included prescription, over-the-counter and complementary and alternative medicines. Around threequarters of study children were exposed to some form of medicinal product before 8 weeks of age. Dermatological preparations were the most commonly used products in young babies. Activated dimeticone, for treatment of colic and flatulence, was given to $16 \%$ of babies and gripe water was used by $13 \%$. Other commonly reported products included oral and topical antifungals and ophthalmic antibiotics. Several OTC products, not licensed for use in this age group, were reported. At each of the older ages surveyed, over $95 \%$ of children had used some form of medicinal product within the previous $12-18$ months. Use of several product categories was higher at 54 months than at 78 or 91 months, such as topical steroids, analgesics (mostly paracetamol) and systemic antibiotics (mainly amoxicillin). Conversely, use of other categories, such as asthma medication, throat preparations (sprays and lozenges) and anti-inflammatory products, increased with increasing age.
\end{abstract}

J. Headley $(\bowtie) \cdot$ K. Northstone

Department of Community-Based Medicine, University of Bristol,

24 Tyndall Avenue,

Bristol BS8 1TQ, UK

e-mail: j.headley@bath.ac.uk
Conclusion Parentally-reported use of medicinal products in the ALSPAC study children appears to be consistent with data from other sources. The use of medicinal products by young children is high and does not always conform to the product labelling.

Keywords Children · Paediatric drug use · Medication . ALSPAC

\section{Introduction}

It is now well recognised that there is a need for more studies to obtain paediatric information on medicines used in children with the aim of reducing the amount of unlicenced and off-label use of medicines in this population. In $2002,15 \%$ of children under 5 and $20 \%$ of children aged 5-15 were reported as having a long-standing illness [13]. In addition, young children may experience a range of relatively minor ailments requiring medical treatment. A previous report using data from this cohort showed that cold, cough, high fever, colic/stomach ache, diarrhoea and vomiting were very common symptoms in the pre-school years, and that cough, cold, earache and high temperature are the most common symptoms to present to medical services [6]. In 2004, 35.7 million prescription items were dispensed in the community for children under 16 at a cost of $£ 293.8$ million [7]. This represents an average of 4.5 items per head in the age range $0-15$ years [7]. The categories of drugs most frequently prescribed for children are antibacterials, analgesics and bronchodilators [12]. Prescribing outside the terms of the product licence occurs in drugs commonly prescribed in general practice such as systemic antibiotics [11]. 
Although children are entitled to free medicines on a National Health Service prescription in the UK, parents may also choose to purchase products over-the-counter (OTC) for various reasons, such as convenience and confusion over their entitlements [2]. In a US survey involving 8,145 3-year-olds, $54 \%$ had been given an OTC medication in the last 30 days, most commonly paracetamol and cough/cold medicines [8], and a Norwegian study concluded that paracetamol was an important tool for parents in managing their children's illnesses [9]. A significant proportion of OTC medicines used in children may be purchased from non-pharmacy outlets, where advice on appropriate use is unavailable [3].

This study describes the patterns of parentally-reported use of all types of medicinal products in a large community sample of young children, at four data collection times between the ages of 4 weeks and 7.5 years.

\section{Methods}

The data for this study were collected as part of the Avon Longitudinal Study of Parents and Children (ALSPAC): a longitudinal study designed to investigate the health and development of children [5]. The study was approved by the ALSPAC law and ethics committee, and the three local research ethics committees.

Pregnant women resident in the three Bristol-based health districts in the former county of Avon in southwest England, and with an expected delivery date falling between 1 April 1991 and 31 December 1992, were eligible to be enrolled. The core ALSPAC sample consists of 14,212 women who had a total of 14,541 study pregnancies, involving 14,676 fetuses, resulting in 14,062 live births. An additional 548 children from 542 eligible pregnancies not included in the core sample were included in the study from age 7. Cohort retention has been good, and we are currently in regular contact with approximately 11,000 families. Further details can be obtained from the ALSPAC website, http://www.alspac.bris.ac.uk.

From various studies performed at the planning stage, the Avon population was considered to be broadly similar to that of the whole of Great Britain. After delivery, the representative nature of the sample was assessed. As in similar studies, the ALSPAC cohort has a slight shortfall in the less affluent families and a shortfall in ethnic minority mothers. Birth weights and lengths and growth measures in ALSPAC are very similar to national standards [5].

The primary source of data collection is via postal questionnaires about the health, development and home environment of the study children completed by each child's main carer, usually the mother. This paper presents data obtained from four such questionnaires administered when the study children were 4 weeks, 54, 78 and 91 months old. Each of these asked questions, designed by the ALSPAC study team, about the use of medicinal products.

The 4-week questionnaire (sent out between 1991 and 1993), asked the baby's mother to: "Please list all the ointments, pills and medicines that have been given to your baby while he/she has been at home. Check: have you included ointments to prevent nappy rash, eyedrops, herbal remedies, etc."

The questionnaire sent out between 1995 and 1997, when the child was 54 months of age ( 4.5 years) asked the following:

1. Children often have accidents or illnesses that need treatment. Please indicate which of the following have been given to your child since he/she was 3 years old
a. Cough medicine
b. Antibiotics/penicillin
c. Throat medicine
d. Vitamins
e. Paracetamol/calpol
f. Ointment for skin
g. Eye ointment
h. Diarrhoea mixture/pills
i. Dimotapp/decongestant
j. Ear drops
k. Eye drops
1. Iron
m. Laxatives
n. Homeopathic medicine
o. Herbal medicine
p. Other

For each category, the carer was asked to tick whether the response was 'Never', 'Yes, for one episode only' or 'Yes, for 2 or more episodes'; and 'If yes, please give full names of substances if you can'.

2. Are there any pills, ointments or medicines that he/she has taken every day or nearly every day for the last 3 months? (Include vitamins, skin cream, inhaler, laxatives as well as antibiotics, homeopathic and herbal remedies, etc.) If yes, please describe.

At 78 months (6.5 years, data collection 1997-1999) and 91 months (7.5 years, data collection 1998-2000) the first question was expanded slightly as follows:

1. Children often have accidents or illnesses that need treatment. Please indicate which of the following have been given to your child in the last 12 months.

a. Cough medicine

b. Antibiotics/penicillin 

c. Throat medicine
d. Vitamins
e. Paracetamol/calpol
f. Ointment for skin
g. Eye ointment
h. Diarrhoea mixture/pills
i. Dimotapp*/decongestant
j. Ear drops
k. Eye drops
1. Iron
m. Laxatives
n. Homeopathic medicine
o. Herbal medicine
p. Asthma medication
q. Vaporiser
r. Other

(*active ingredients: brompheniramine, phenylephrine and phenylpropanolamine)

The tick box response options, the request for full name of the product, and the second question were the same as at 54 months.

After a questionnaire was sent out, if a response was not received within 3 weeks, a reminder letter was sent. If the questionnaire had still not been received after a further 2 weeks, a second reminder letter was sent. Finally, if no response had been received after 3 months, a member of the study team either rang the mother or visited her home, and encouraged or helped her to complete the questionnaire. The date of completion is included on each questionnaire, so whilst all returned questionnaires are added to the database and included in the overall response rate, those that were completed after a defined cut-off date can be excluded from individual analyses.

Most of the self-completion responses on the questionnaires are self-coding-the ticked reply box contains a printed number that can be directly keyed. However, the actual names of medicinal products used (including vitamins and supplements, herbal products, homeopathic remedies, over-the-counter and prescription products) were collected as free text responses.

An ALSPAC drug dictionary has been developed based on the World Health Organisation (WHO) Drug Dictionary (first quarter 2000 version, provided free of charge by the Uppsala Monitoring Centre). The ALSPAC dictionary assigns a Drug Name and Anatomical-Therapeutic-Chemical (ATC) classification as described in the WHO Drug Dictionary to an individual product. The latter classification groups medications according to the organ or body system on which they are designed to act and their chemical, pharmacological and therapeutic properties. Some drugs have several ATC codes as they can be used in different preparations on different body systems. The ALSPAC dictionary codes preparations, and thus a single ATC, has been assigned to each product. In the few cases where more than one ATC code would have been possible, a decision was made as to the most likely use in this population. Additional details about the WHO Drug Dictionary can be found on the WHO website: http://www.whocc.no/atcddd/.

In cases where a category of medicinal product was ticked as having been used but no further details were provided, a non-specific code for that category has been added to the database of text responses.

For the purposes of this report, all responses indicating that a product in the defined category had been used have been included, thus indicating 'ever use' of these categories of medicinal products rather than taking into account frequency of use.

\section{Results}

The response rate was good: Table 1 gives the number of questionnaires mailed and returned at each age. The majority of questionnaires were completed at or close to the intended age. For example, $90 \%$ of the returned month 54 questionnaires had been completed by 55 months and $99 \%$ by 58 months, so all data from the 54-91 month questionnaires have been included. However, as the purpose of the question at 4 weeks was to ascertain what medicinal products were used on the study children as very young babies, a cut-off was applied so that only questionnaires completed before the child was 8 weeks old were included. Using this criterion, at least one questionnaire was completed for 12,525 study children and all 4 were completed for 6,635 children.

For most of the defined categories, the number of tick box responses not supported with a text response giving the name of the product increased between the ages of 54 and 91 months (at 4 weeks, responses to the medication question were all collected as free text).

The week 4 questionnaire was completed before the child was 8 weeks of age in 10,897 cases $(80 \%$ of those sent, $88 \%$ of those returned). Around three-quarters of study children were exposed to some form of medicinal product before 8 weeks of age. At this age, dermatological products were most commonly reported, mainly those for treatment and protection against nappy rash, such as 'Sudocrem', a proprietary product containing zinc oxide used in $29 \%$ of babies, and zinc and castor oil cream used in $22 \%$. Simeticone (activated dimeticone) in products for treatment of colic and flatulence, such as 'Infacol', was given to $16 \%$ of babies. Gripe water (terpeneless dill seed oil and sodium bicarbonate) was used in $13 \%$ of the cohort. Other commonly reported products included oral and topical antifungals and ophthalmic antibiotics (mostly 
Table 1 Total number of medicinal products recorded per child at each age

4 weeks 54 months 78 months 91 months ( $<8$ weeks)

\begin{tabular}{|c|c|c|c|c|}
\hline $\begin{array}{l}\text { No. of } \\
\text { questionnaires } \\
\text { sent out }\end{array}$ & 13,659 & 12,374 & 10,914 & 11,251 \\
\hline $\begin{array}{l}\text { No. of completed } \\
\text { questionnaires }\end{array}$ & $10,897^{\mathrm{a}}$ & 9,725 & 8,578 & 8,269 \\
\hline \multicolumn{5}{|c|}{ Total no. products recorded per child } \\
\hline 0 & 2,573 & 129 & 339 & 410 \\
\hline 1 & 3,029 & 557 & 1,010 & 1,139 \\
\hline 2 & 2,594 & 1,400 & 1,746 & 1,911 \\
\hline 3 & 1,502 & 2,020 & 1,715 & 1,759 \\
\hline 4 & 687 & 1,834 & 1,370 & 1,317 \\
\hline 5 & 320 & 1,382 & 1,001 & 771 \\
\hline 6 & 130 & 939 & 590 & 451 \\
\hline 7 & 39 & 578 & 346 & 227 \\
\hline 8 & 13 & 352 & 179 & 133 \\
\hline 9 & 10 & 205 & 139 & 77 \\
\hline 10 & & 103 & 51 & 43 \\
\hline 11 & & 74 & 33 & 32 \\
\hline 12 & & 49 & 24 & 12 \\
\hline 13 & & 30 & 13 & 7 \\
\hline 14 & & 25 & 6 & 7 \\
\hline 15 & & 16 & 10 & 6 \\
\hline 16 & & 19 & 1 & 9 \\
\hline 17 & & 10 & 1 & 32 \\
\hline 18 & & 1 & 2 & 5 \\
\hline 19 & & 0 & 0 & 2 \\
\hline 20 & & 2 & 1 & \\
\hline 21 & & 1 & 0 & \\
\hline 22 & & & 0 & \\
\hline 23 & & & 1 & \\
\hline
\end{tabular}

${ }^{a}$ Completed within 8 weeks of birth

chloramphenicol). A few babies (2.3\%) were given vitamin drops. Some were given herbal drinks (2.2\%), homeopathic products $(1.2 \%)$ and a variety of topical complementary and alternative medicine products, such as calendula and camomile creams $(3.3 \%)$.

Several OTC products not licensed for use in this age group were reported. For example, inhalant decongestant products not licensed for children under 3 months of ageSnuffle-babe Vapour Rub (eucalyptus oil, menthol and thyme oil), Karvol Decongestant Capsules for inhalation (levomenthol with chlorobutanol, pine oils, terpineol and thymol) and Vicks Vaporub (levomenthol, camphor, eucalyptus oil and turpentine oil) - were used in over $6 \%$ of the cohort, and xylometazoline nasal spray was used on $0.6 \%$. Calpol (paracetamol), which is licensed from 2 months, was given to over $1 \%$ when they were under 8 weeks old.

At the older ages, 54, 78 and 91 months, 9,728 (78\% of those mailed), 8,578 (78\%) and 8,269 (73\%) questionnaires were completed and returned, respectively. In these latter questionnaires, relatively few children were reported not to have used any medicinal products in the preceding $12-18$ months. At 54 months (4.5 years), only 129 children (1.3\% of those returning the questionnaire) were not reported as having used a medicinal product since the age of 3. At 78 and 91 months, the figures were $339(4.0 \%)$ and 329 (4.0\%), respectively. Table 1 shows the number of products reported per child at each age.

Table 2 shows the frequency of use of medicinal products, by ATC code, at each data collection time. The data are presented as the total number of drugs reported in an ATC class per number of children in which any products within this class were used (i.e. more than one product in a class may have been reported per child). The pattern of use of different categories of medicinal product varied with age. Usage of several product categories was higher at 54 months than at 78 or 91 months. For example, at 54 months, 1,052 children $(10.2 \%)$ were reported to have used topical steroids (mostly hydrocortisone) compared with $7.4 \%$ at 78 months and $4.9 \%$ at 91 months. Paracetamol (as a single ingredient) was recorded for 9,211 children $(94.7 \%)$ at 54 months, 7,595 $(88.5 \%)$ at 78 months and $7,247(87.6 \%)$ at 91 months. In addition, systemic antibiotics (mainly amoxicillin), laxatives (mostly lactulose), treatments for diarrhoea (mainly rehydration salts), various cough and cold products, emollient and protective skin preparations (mostly paraffin-based proprietary products), topical antipruritics, antihistamines and local anaesthetic products were all greater at 54 months than at the older ages. Conversely, use of other categories, such as throat preparations (sprays and lozenges), and anti-inflammatory products, increased with increasing age. Use of 'asthma' medication (mainly salbutamol and beclomethasone) also increased with increasing age; at 54 months, $6.8 \%$ of the cohort reported use of anti-asthmatics, by 78 months this had increased to $12.0 \%$ and to $14.2 \%$ at 91 months. Of the 1,174 children reported as having used asthma medication at 91 months, 1,038 (88\%) had previously had a diagnosis of 'asthma' from a doctor and 907 (77\%) reported having asthma in the past 12 months.

Treatments for less common conditions were also reported by this community sample. By 91 months, 6 children were using insulin, 17 reported methylphenidate (for attention deficit hyperactivity disorder) and 2 reported thyroid therapy. At 54 months, 28 children reported antiepileptic medication but this had reduced to 15 children by 91 months.

Between 54 and 91 months, a very small number of children were reported to have been given an OTC medicine, whilst they were younger than the age specified on the Patient Information Leaflet or Summary Product Characteristics, for example, aspirin, 'Dequadin' lozenges (dequalinium chloride), 'Night Nurse Liquid' (paracetamol, pomethazine hydrochloride, dextromethorphan hydrobromide) and 'Diocalm' (morphine hydrochloride and attapulgite). 
Table 2 Frequency of use of medicinal products, by ATC code, at each age. Total number of drugs reported in a class/number of children in which this class of product was used (individual children may have used more than one product in a class). ATC level 1 (in bold) includes all reported cases. ATC level 2 is given where 10 or more children reported a product in this category in at least one questionnaire

\begin{tabular}{|c|c|c|c|c|c|}
\hline \multirow[t]{2}{*}{ ATC code } & & $<8$ weeks & 54 months & 78 months & 91 months \\
\hline & \multicolumn{4}{|l|}{ ATC text } & 8,269 \\
\hline $\mathbf{A}$ & Gastrointestinal preparations & $4,470 / 3,416$ & $6,733 / 4,188$ & $4,747 / 3,130$ & $4,262 / 2,973$ \\
\hline A01 & Stomatological preparations & $691 / 649$ & $114 / 94$ & $57 / 46$ & $35 / 30$ \\
\hline A02 & $\begin{array}{l}\text { Antacids, drugs for peptic ulcer } \\
\text { and flatulence }\end{array}$ & $3,422 / 2,690$ & $31 / 27$ & $25 / 23$ & $15 / 13$ \\
\hline A03 & $\begin{array}{l}\text { Antispasmodics, anticholinergics } \\
\text { and propulsives }\end{array}$ & $29 / 29$ & $13 / 12$ & $13 / 11$ & $9 / 9$ \\
\hline A06 & Laxatives & $41 / 41$ & $528 / 421$ & $277 / 200$ & $328 / 262$ \\
\hline A07 & $\begin{array}{l}\text { Antidiarrhoeals, intestinal } \\
\text { anti-inflammatories and } \\
\text { anti-infectives }\end{array}$ & $39 / 38$ & $693 / 682$ & 196/191 & $227 / 224$ \\
\hline A11 & Vitamins & $247 / 247$ & $5,169 / 3,567$ & $3,143 / 2,121$ & $3,748 / 2,692$ \\
\hline A12 & Mineral supplements & $1 / 1$ & $170 / 155$ & $40 / 27$ & $158 / 149$ \\
\hline B & Blood and blood forming organs & $61 / 47$ & $\mathbf{5 7 / 5 0}$ & $28 / 21$ & $32 / 25$ \\
\hline B03 & Antianaemic preparations & $46 / 32$ & $48 / 41$ & $28 / 21$ & $31 / 24$ \\
\hline C & Cardiovascular system & $13 / 11$ & $6 / 5$ & $8 / 7$ & $4 / 3$ \\
\hline D & Dermatologicals & $9,618 / 6,397$ & $5,105 / 3,269$ & $3,538 / 2,653$ & $2,988 / 2,441$ \\
\hline $\mathrm{D}$ & Dermatologicals unspecified & $25 / 24$ & $1,015 / 1,010$ & $915 / 907$ & $1,376 / 1,373$ \\
\hline D01 & Antifungals for dermatological use & $584 / 557$ & $173 / 163$ & $185 / 173$ & $125 / 118$ \\
\hline D02 & Emollients and protectives & $7,908 / 5,655$ & $1,954 / 1,453$ & $12,18 / 928$ & $690 / 519$ \\
\hline D04 & $\begin{array}{l}\text { Antipruritics, including antihistamines, } \\
\text { anaesthetics }\end{array}$ & $6 / 6$ & $158 / 151$ & $91 / 89$ & $59 / 57$ \\
\hline D06 & Antibiotics and chemotherapeutics, topical & $98 / 95$ & $169 / 161$ & $154 / 142$ & $107 / 99$ \\
\hline D07 & Corticosteroids, topical & $125 / 121$ & $1,358 / 1,052$ & $790 / 631$ & $507 / 408$ \\
\hline D08 & Antiseptics and disinfectants & $843 / 785$ & $246 / 223$ & $161 / 154$ & $114 / 110$ \\
\hline D11 & Other dermatological preparations & $25 / 25$ & $16 / 14$ & $11 / 11$ & $3 / 3$ \\
\hline G & $\begin{array}{l}\text { Genito-urinary system and sex } \\
\text { hormones }\end{array}$ & $1 / 1$ & $17 / 15$ & $18 / 16$ & $9 / 8$ \\
\hline $\mathbf{H}$ & Systemic hormones, excl sex hormones & $3 / 3$ & $69 / 59$ & $63 / 56$ & $49 / 40$ \\
\hline H01 & $\begin{array}{l}\text { Pituitary, hypothalamic hormones } \\
\text { and analogues }\end{array}$ & 0 & $2 / 2$ & $12 / 8$ & $14 / 11$ \\
\hline H02 & Corticosteroids for systemic use & $1 / 1$ & $64 / 55$ & $48 / 46$ & $34 / 28$ \\
\hline $\mathbf{J}$ & General anti-infectives for systemic use & $354 / 341$ & $6,505 / 5,976$ & $3,322 / 3,151$ & $2,434 / 2,358$ \\
\hline $\mathrm{J} 01$ & Antibacterials for systemic use & $346 / 335$ & $6,498 / 5,973$ & $3,309 / 3,146$ & $2,419 / 2,349$ \\
\hline $\mathbf{L}$ & $\begin{array}{l}\text { Antineoplastic and immunomodulating } \\
\text { agents }\end{array}$ & $\mathbf{0}$ & $\mathbf{0}$ & $1 / 1$ & $2 / 1$ \\
\hline M & Musculo-skeletal system & $\mathbf{0}$ & $63 / 62$ & $111 / 107$ & $119 / 118$ \\
\hline M01 & $\begin{array}{l}\text { Anti-inflammatory and antirheumatic } \\
\text { products }\end{array}$ & 0 & $62 / 61$ & $105 / 103$ & $117 / 116$ \\
\hline $\mathbf{N}$ & Nervous system & $163 / 159$ & $9,561 / 9,184$ & $7,857 / 7,620$ & $7,400 / 7,261$ \\
\hline N02 & Analgesics & $157 / 154$ & $9,510 / 9,181$ & $7,802 / 7,616$ & $7,344 / 7,256$ \\
\hline N03 & Anti-epileptics & $1 / 1$ & $39 / 28$ & $38 / 21$ & $25 / 15$ \\
\hline N06 & $\begin{array}{l}\text { Psychoanaleptics (antidepressants/ } \\
\text { stimulants) }\end{array}$ & $1 / 1$ & $4 / 2$ & $5 / 5$ & $24 / 17$ \\
\hline $\mathbf{P}$ & $\begin{array}{l}\text { Antiparasitics, insecticides and } \\
\text { repellents }\end{array}$ & $\mathbf{0}$ & $87 / 80$ & $90 / 84$ & $58 / 54$ \\
\hline $\mathrm{P} 02$ & Anthelmintics & 0 & $66 / 65$ & $62 / 59$ & $37 / 36$ \\
\hline $\mathrm{P} 03$ & $\begin{array}{l}\text { Ectoparasiticides, scabicides, insecticides, } \\
\text { repellents }\end{array}$ & 0 & $14 / 13$ & $22 / 22$ & $17 / 16$ \\
\hline $\mathbf{R}$ & Respiratory system & $1,168 / 1,032$ & $9,609 / 6,995$ & $8,615 / 5,492$ & $7,796 / 5,131$ \\
\hline R01 & Nasal preparations & $468 / 456$ & $705 / 655$ & $437 / 391$ & $403 / 382$ \\
\hline $\mathrm{R} 02$ & Throat preparations & 0 & $471 / 471$ & $514 / 511$ & $649 / 646$ \\
\hline
\end{tabular}


Table 2 (continued)

\begin{tabular}{|c|c|c|c|c|c|}
\hline \multirow[t]{2}{*}{ ATC code } & & $<8$ weeks & 54 months & 78 months & 91 months \\
\hline & $\begin{array}{l}\text { No. of questionnaires returned with data } \\
\text { ATC text }\end{array}$ & 10,897 & 9,725 & 8,578 & 8,269 \\
\hline R03 & Anti-asthmatics & 0 & $1,178 / 658$ & $2,422 / 1,029$ & $1,920 / 1,174$ \\
\hline R05 & Cough and cold preparations & $697 / 643$ & $7,839 / 6,434$ & $5,058 / 4,678$ & $4,684 / 4,391$ \\
\hline R06 & Antihistamines for systemic use & $3 / 3$ & $216 / 186$ & $184 / 163$ & $140 / 127$ \\
\hline $\mathbf{S}$ & Sensory organs & $1496 / 1411$ & $2954 / 2213$ & $1051 / 884$ & $1090 / 861$ \\
\hline S01 & Ophthalmologicals & $1,316 / 1,257$ & $1,852 / 1,444$ & $536 / 438$ & $633 / 499$ \\
\hline S02 & Otologicals & $3 / 3$ & $737 / 728$ & $426 / 416$ & $405 / 403$ \\
\hline S03 & $\begin{array}{l}\text { Ophthalmological and otological } \\
\text { preparations }\end{array}$ & $177 / 177$ & $365 / 314$ & $89 / 84$ & $52 / 49$ \\
\hline V & Various & $855 / 705$ & $1,082 / 745$ & $955 / 705$ & $1,139 / 796$ \\
\hline V03 & $\begin{array}{l}\text { All other therapeutic products } \\
\text { (including CAM) }\end{array}$ & $587 / 504$ & $1,079 / 744$ & $954 / 704$ & $1,138 / 795$ \\
\hline V07 & $\begin{array}{l}\text { All other non-therapeutic products } \\
\text { (eg baby toiletries) }\end{array}$ & $295 / 214$ & 0 & $1 / 1$ & 0 \\
\hline
\end{tabular}

\section{Discussion}

The advantage of collecting data on children's use of medicinal products from their parents/carers, as opposed to from medical records and prescription databases, is that the former are in a position to know what was actually given to their children, rather than what may have been prescribed but not collected or taken by the child. In addition, the data potentially includes medication obtained from all sourcesGP's, pharmacies, supermarkets, CAM practitioners, friends, relatives and neighbours. However, potential issues include the accuracy of recall (especially over long periods of 12-18 months, as used at the older ages in this study) and parental knowledge and understanding about the medicines given to their child.

These data were collected over the period 1991-2000. Between 1994 and 1998, the annual number of children aged 5-15 years prescribed antibacterial drugs ranged from 322 to 402 per 1,000 [12]. This compares favourably with the current study where the number reporting use of antibiotics over the previous 12 months was 367 per 1,000 at 6.5 years of age. At 7.5 years, the rate was lower at 284 per 1,000 , but these latter data reflect use of antibiotics between 1997 and 2000, when a substantial decline occurred in the prescribing of antibiotics by general practitioners, in an effort to curb the spread of antibiotic resistance [14]. Children under 5 are known to be the greatest users of antibiotics [10, 12], and the data from this study are consistent with this in that antibiotic use reported at 4.5 years was considerably greater than at 6.5 and 7.5 years.

The number of children aged 5-15 years prescribed bronchodilators over the period 1994-1998 ranged between 135 and 141 per 1,000 boys and 113-118 per 1,000 girls [12]. The prevalence of treated asthma in the same age group was $128-132$ per 1,000 boys and $100-106$ per 1,000 girls, and around $94 \%$ of these are prescribed bronchodilators [12]. In this study, the reported use of all 'asthma' medication for boys and girls combined was 120 per 1,000 at 6.5 years and 142 per 1,000 at 7.5 years. Thus, the figures from this study do not suggest a lack of recall. Indeed, at 7.5 years, the reported use of asthma medication is slightly higher than the national figures. However, as the latter combine data over a 10-year age range (5-15 years) any differences at individual ages may be masked.

Therefore, as the questionnaire data on use of prescribed antibiotics and anti-asthmatics in this study is in the range expected from prescription data, parentally-reported use of non-prescription medication in this cohort is also likely to be reasonably reliable.

The findings suggest that most children use some form of medication from a very young age. Medicines available over-the-counter were widely used, although it was not possible to determine from these data whether they were actually purchased over-the-counter or prescribed. The reason for use was not collected, so it was also not possible to assess to what extent products were appropriately used. For example, paracetamol has been found to be used by parents to calm and settle their children and aid sleep $[1,9]$. Some products were used in children younger than the age for which they were licensed. It was not possible to assess general adherence to information given in the patient information leaflets or whether advice was sought prior to using a product outside the specifications, but parents of young children should be encouraged to follow the labelling advice or seek advice from a health professional.

The ALSPAC database provides a resource to investigate the use of commonly used medications with later health and 
development; for example paracetamol, which is widely used and may be associated with development of asthma [4]. Future work may also examine differences in usage by sex of the child and socio-economic status of the parents.

Acknowledgements We are extremely grateful to all the families who took part in this study, the midwives for their help in recruiting them, and the whole ALSPAC team, which includes interviewers, computer and laboratory technicians, clerical workers, research scientists, volunteers, managers, receptionists and nurses. The UK Medical Research Council, the Wellcome Trust and the University of Bristol provide core support for ALSPAC. The study complies with current British law and was subject to ethics approval. This publication is the work of the authors and J. Headley will serve as guarantor for the contents of this paper.

\section{References}

1. Allotey P, Reidpath DD, Elisha D (2004) "Social medication" and control of children: a qualitative study of over-the-counter medication among Australian children. Pediatrics 114:e378-e383

2. Birchley N, Conroy S (2002) Parental management of over-thecounter medicines. Paediatr Nurs 14:24-28

3. Conroy S, Collier J, Birchley N, Neil K, Rodgers S, McIntyre J, Choonara I, Avery A (2003) An examination of the risk management issues in the handling at home of over-the-counter medicines purchased for children. Pharm J 271:209-213

4. Fogarty A, Davey G (2005) Paracetamol, antioxidants and asthma. Clin Exp Allergy 35:700-702
5. Golding J, Pembrey M, Jones R; The ALSPAC Study Team (2001) ALSPAC - The Avon Longitudinal Study of Parents and Children I. Study methodology. Paediatr Perinat Epidemiol 15:74-87

6. Hay A, Heron J, Ness AR; The ALSPAC Study Team (2005) The prevalence of symptoms and consultations in pre-school children in the Avon Longitudinal Study of Parents and Children (ALSPAC). Fam Prac 22:367-374

7. Health and Social Care Information Centre (2005) Prescriptions Dispensed in the Community: statistics for 1994 to 2004: England. http://www.dh.gov.uk/PublicationsAndStatistics/

8. Kogan MD, Pappas G, Yu SM, Kotelchuck M (1994) Over-thecounter medication use among US preschool-age children. JAMA 272:1025-1030

9. Lagerlov P, Helseth S, Holager T (2003) Childhood illnesses and the use of paracetamol (acetaminophen): a qualitative study of parents' management of common childhood illnesses. Fam Prac 20:717-723

10. Majeed A, Moser K (1999) Age- and sex-specific antibiotic prescribing patterns in general practice in England and Wales in 1996. Br J Gen Pract 49:735-736

11. McIntyre J, Conroy S, Avery A, Corns H, Choonara I (2000) Unlicensed and off label prescribing of drugs in general practice. Arch Dis Child 83:498-501

12. Office for National Statistics (2000) Key Health Statistics from General Practice 1998. (Series MB6 No 2). https://www.statistics.gov.uk/

13. Office for National Statistics (2004) Living in Britain. No 31 Results from the 2002 General Household Survey. London: TSO. http://www.statistics.gov.uk/lib2002/downloads/health.pdf

14. Sharland M, Kendall H, Yeates D, Randall A, Hughes G, Glasziou P, Mant D (2005) Antibiotic prescribing in general practice and hospital admissions for peritonsillar abscess, mastoiditis, and rheumatic fever in children: time trend analysis. BMJ 331:328-329 